\title{
POLLEN TUBES GROWTH FOLLOWING SELF- AND CROSS- POLLINATION IN Melaleuca alternifolia (Maiden \& Betche) Cheel
}

\author{
Liliana Baskorowati ${ }^{1}$
}

\begin{abstract}
Pollen tubes growth following controlled self- and cross-pollination of several individual of trees of Melaleuca alternifolia was observed under fluorescence microscope. Two experiments during 2004 and 2005 flowering seasons were carried out at M. alternifolia seed orchard at West Wyalong, New South Wales (Australia). Pollen tubes number was investigated at 4, 7, 9 and 14 days after pollination by fluorescence microscope. Ovule penetration by pollen tubes was investigated 14 days after pollination. They varied greatly between self- and cross-pollen tubes in the style, with less pollen tube found in the self-pollinated styles than cross-pollinated styles. The mean number of pollen tubes declined significantly as interval to harvesting of the style increased, from a maximum at the 4 days after pollination. The availability of self-pollen tubes grow in the style of $M$. alternifolia shows that mechanism of self-incompatibility occurs in this species. The reduction of number of pollen tubes in the lower parts of style shows that the self-incompatibility systems operate in the stigma or the style. The rejection of self-pollen tubes at the ovarian level and the consequent low levels or intolerance of selfing maintains a high level of outcrossing in M. alternifolia.
\end{abstract}

Keywords: Melaleuca alternifolia, pollen tubes, self-incompatibility, self-pollination, crosspollination

\section{INTRODUCTION}

Self-incompatibility is a common characteristic of many flowering plants (Bawa, 1974; Bawa and Beach, 1983). Self-incompatibility may result from a variety of mechanisms, such as the failure of self pollen grains to adhere to the stigma or the failure of pollen tubes to grow down the style (de Nettacourt, 1977; Richard, 1997). There have been reported of more than one self-incompatibility mechanism operating in a species, which may act both the pre- and post-zygotic levels (Sedgley and Griffin, 1989). For example, Eucalyptus spathulata and E. platypus have both pre- and post-zygotic barriers to self pollinated seed production as pollen tube penetration of ovules and ovules fertilization was reduced following self-compared with cross-pollination, and few self-fertilised ovules developed past zygote division (Sedgley and Granger, 1996). The genetic control of a pre-zygotic incompatibility system may be either gametophytic when the incompatibility of phenotype of the pollen is determined by its haploid genome - or sporophytic when the pollen

Center for Forest Biotechnology and Tree Improvement Research, Jl. Palagan Tentara Pelajar Km. 15, Purwobinangun, Pakem, Sleman, Yogyakarta, Indonesia. E-mail: lbaskorowati@yahoo.com. 
exhibits the incompatibility phenotype of its diploid parent (de Nettacourt, 1977; Sedgley and Griffin, 1989; Richard, 1997; Franklin-Tong and Franklin, 2003).

Barlow and Forrester (1984), in a study of several compatible intraspecific crosses of Melaleuca species, reported that gametophytic self-incompatibility occurs in these species. They also noted that self-pollen tubes of Melaleuca bypericifolia and $M$. thymifolia arrest in the ovary, whereas those of $M$. capitata arrest in the micropyle. Seavy and Bawa (1986) and Sage et al. (1994) characterized the failure of selfed flowers to produce fruits, despite the self-pollen tube growing successfully in the style to the ovary, as the phenomenon of late-acting self-incompatibility. This has been reported to occur in several Myrtaceous species such as in Eucalyptus regnans (Sedgley et al., 1989), E. cladocalyx and E. leptophylla (Ellis and Sedgley, 1992), E. nitens (Pound et al., 2003), and E. globulus (Pound et al., 2002a; 2002b).

A recent study on $M$. cajuputi ssp. cajuputi in a seedling seed orchard in Yogjakarta, Indonesia, found that this species has a low level of self-incompatibility (0.035), although some individual trees were completely self-compatible (Kartikawati, 2005). However, several studies have noted that the mechanisms controlling preferential outcrossing, which reduce inbreeding and promote heterozygosity, vary between species (Sedgley and Griffin, 1989; Potts and Gore, 2000). Results from previous studies of Melaenca species (Barlow and Forrester, 1984; Kartikawati, 2005) lead to the hypothesis that self-incompatibility mechanisms operate in M. alternifolia.

Melaleuca alternifolia, which flowers annually during spring (Baskorowati, 2008), is considered to have a breeding system that is preferentially outcrossing, although selfing is not uncommon (Butcher et al., 1992; Rosseto et al., 1999; Doran and Moran, 2002). Information on the level and the mechanisms of self-incompatibility is essential to determine the best breeding strategy for M. alternifolia. However, published studies on the mating system of M. alternifolia (Butcher et al. 1992; Rosseto et al. 1999; Doran and Moran 2002) provided very limited information on the level of selfing. The mechanism by which self-incompatibility acts in $M$. alternifolia is unknown, as is the impact of selfing on capsule, seed and seedling development. Therefore, this paper reports investigation of pollen tubes growth in M. alternifolia pistils following controlled self- and cross-pollination to find out whether self-incompatibility mechanism operates in this species.

\section{MATERIALS AND METHODS}

\section{A. Location}

Fieldwork to provide the materials of which to be investigated selfincompatibility on the basis of pollen tube growth was undertaken in West Wyalong (the second-generation Seedling Seed Orchard), New South Wales, Australia during the flowering season of November 2005 and November 2006. Subsequent laboratory work was carried out in the electron microscopic unit (EMU) of the 
Research School of Biological Sciences (RSBS), Australian National University, Canberra. Pollen tube observation was carried out twice due to the number of flowers limitation during the flowering season.

The first experiment was undertaken in November 2005. A reciprocal mating design was used in this study: one individual of each of families 32 and 99 was crossed in each direction with an individual of the other, and both individuals were self-pollinated. However, due to limitation of flower available on those trees, families (32, 48, and 53) were used in the second experiment (November 2006).

\section{B. Pollination}

Methods for controlled cross- and self-pollination used were as described by Baskorowati (2006). The treatment on the first experiment comprised two pollen treatments; pollen from the same tree (self-pollination) and pollen from different tree (cross-pollination). The treatments in the second experiment comprised of cross-pollination ( $32 \times$ polymix, $48 \times$ polymix, and $53 \times$ polymix), self-pollination ( $32 \times 32,48 \times 48$, and $53 \times 53$ ) and open-pollination (each of 32, 48, and 53). In this experiment, a polymix comprising a mixture of pollen from 4 unrelated families collected during the November 2005 flowering season was used. The pollen mix, comprising pollen from family numbers 12, 15, 50, and 99 was 12 months old, and had been stored in a deep freezer at $-18^{\circ} \mathrm{C}$. A pollen viability test undertaken before pollination, it was found to have a mean germination percentage of $49 \%$. Pollen viability was tested using liquid medium in-vitro techniques (Griffin et al., 1982). Pollen was incubated at $25^{\circ} \mathrm{C}$ in a solution of $30 \%$ sucrose to which was added 150 ppm of boric acid. Approximately $0.2 \mathrm{ml}$ of the solution was transferred into a vial, and then a small amount of pollen picked up using a toothpick, was added to the vial. The vials were shaken, labelled and incubated at $25^{\circ} \mathrm{C}$. Germination was recorded after 24 hours by counting the pollen grains under a microscope at $40 \mathrm{X}$ magnification. A minimum of 50 flowers per treatment per tree were emasculated, pollinated and bagged. Each flower of $M$. alternifolia consists of four petals, four sepals, and five staminal columns from which numerous anthers are attached by short filaments, a single style and stigma; each flower has three carpels with numerous ovules (Baskorowati, 2008).

\section{Field harvest and microscopy}

A minimum of 10 pollinated flowers per treatment per tree were harvested at $1,2,3,4,7$, and 9 days after pollination in the November 2005 fieldwork, and at 4, 7,9 , and 14 days after pollination in the November 2006 fieldwork. The harvesting intervals were determined based on the results of previous studies of Myrtaceous species: Leptospermum sp. (O'Brien, 1994), E. globulus (Pound et al., 2002a), and E. nitens (Pound et al., 2003). A minimum of 25 flowers subject to open-pollination were also collected on the $14^{\text {th }}$ day after they had opened during the November 2006 observations. 
The style and hypanthium from each treatment were fixed in Carnoy's fixative ( $6: 3: 1$ absolute ethanol : chloroform : glacial acetic acid) for a minimum of 24 hours, transferred to $75 \%$ ethanol, and stored in a deep freezer $\left(-18^{\circ} \mathrm{C}\right)$. Prior to examination, the fixed material was dehydrated through an alcohol series $(90 \%, 70 \%$, and $30 \%$ ), and then softened in $0.1 \mathrm{~N}$ sodium hydroxide at $60^{\circ} \mathrm{C}$ for a minimum of 5 hours, stained with decolorized aniline blue overnight (Martin, 1959), and prepared for observation under a microscope.

Individual styles were incised longitudinally and the skin of the hypanthium was dissected and incised longitudinally so that the ovules could be seen clearly. A small amount of PBS (phosphate buffered saline) solution was added to the slides, and the styles were then gently squashed onto microscopy slides. All ovules from each locule were mounted onto microscope slides. The slides were observed using fluorescence microscopy; these slides could be stored in a refrigerator for up to 3 days to allow for subsequent observation.

A single count of the number of pollen tubes in each style was made at the top, middle and bottom of the style using a counter, under a Zeiss Axiophot microscope in fluorescence mode. The total number of pollen tubes penetrating the ovules was also recorded.

\section{Statistical Analysis}

Restricted (or residual) maximum likelihood (REML) was used as a model for analyzing the data. This approach was used in preference to analysis of variance (ANOVA) as it is capable of handling unbalanced data. The numbers of pollen tubes were transformed into square roots to meet a normal distribution assumption. The number of pollen tubes was set as response variate and seedlots, position of observation, days to harvesting to styles were set as fixed effects. All analyses were performed with the statistical package GenStat.

The model was: $\mathrm{Yij}=\mu+\rho \mathrm{i}+\tau \mathrm{j}+\varepsilon \mathrm{ij}$

Yij $=$ observation

$\mu=$ overall mean

$\rho \mathrm{i}=$ replicate effect

$\tau j=$ treatment effect

हij $=$ residual

\section{RESULTS AND DISCUSSION}

\section{A. First Experiment}

The maximum number of tubes at the three positions (top, middle, and bottom) of style in the first experiment (November 2005) was recorded 4 days after pollination. Pollen grains had germinated on the stigma of the styles harvested at 1,2 , and 3 days after pollination; however, only low numbers of pollen tubes 
grew down the styles towards the ovary. Therefore, results of the pollen tube growth assessment described here focus on styles harvested at 4, 7, and 9 days after pollination. In general, pistils from all types of pollination observed at 4, 7, and 9 days following pollination showed straight pollen tubes located within pollen tube walls (Figure 1.A). However, abnormalities were evident in the styles and in the ovules of several self-pollinated pollen tubes. Abnormalities included disoriented pollen tubes, multiple small tube clusters, and abortion (Figure 1.A and 1.B). These abnormalities are often used as indicator in incompatibilities (O'Brien, 1994).

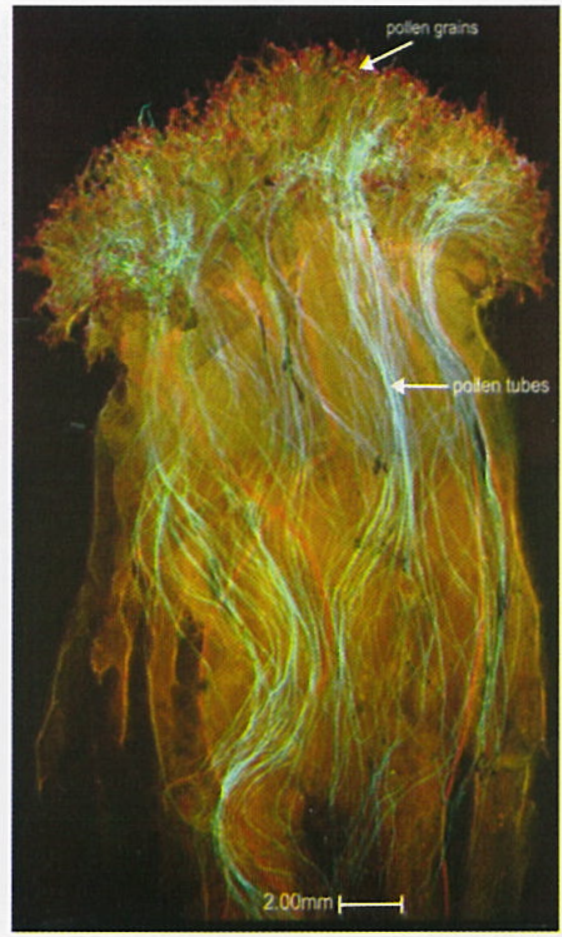

A

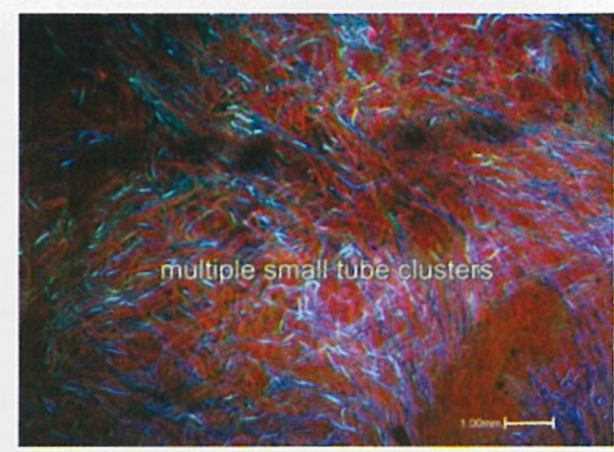

B

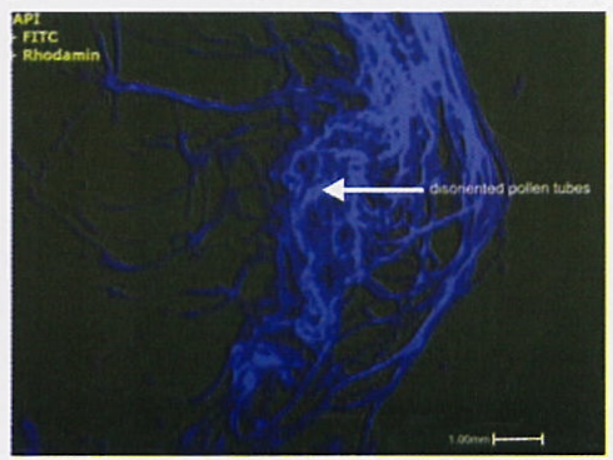

C

Figure 1. Fluorescence micrographs of pollen tubes growth on pistil of $M$. alternifolia, stained with decolourized aniline blue. A: 4 days after crosspollination; B and C: 4 days after self-pollination

Results for the pollination treatments show that the average number of pollen tubes over the 3 positions in the style at 7 days after pollination, varied between crosses in the treatments (Figure 2; Wald stat $=114.4$, d.f. $=3, \chi=<0.001$ ), for both self-pollination and cross-pollination. The average number of pollen tubes following cross-pollination was greater than that from self-pollination. 


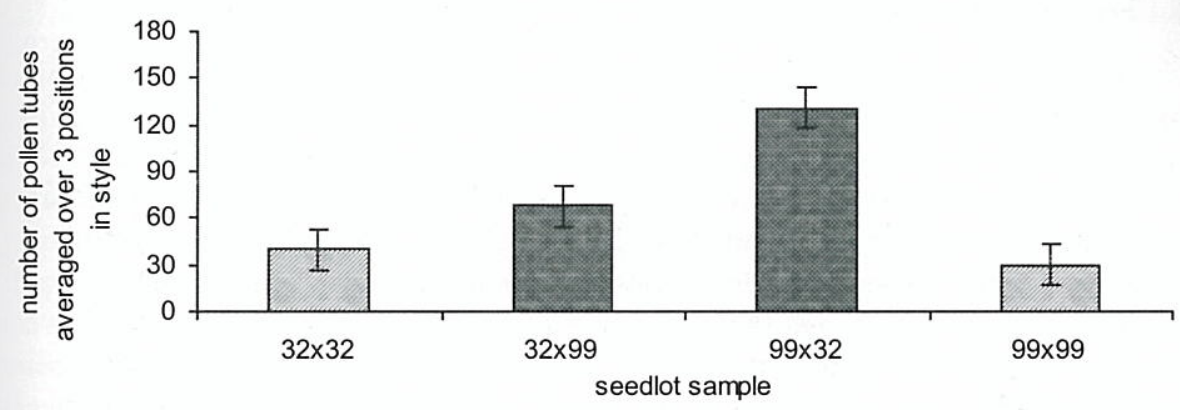

Figure 2. The average number of pollen tubes over 3 positions in style, and associated standard errors, for self- and cross-pollination treatments (November 2005)

The period elapsed from pollination to style harvesting significantly influenced the average number of pollen tubes in the style (Figure 3; Wald stat $=27.1$, d.f. $=2$, $\chi=<0.001)$; the average number of pollen tubes declined significantly as interval to harvesting of the style increased, from a maximum at the $4^{\text {th }}$ day after pollination. The number of pollen tubes also varied with position in the style (Figure 4; Wald stat $=98.6$, d.f. $=2, \chi=<0.001$ ); the mean number of pollen tubes in the middle of the style was greater than those in the upper and lower parts of the style.

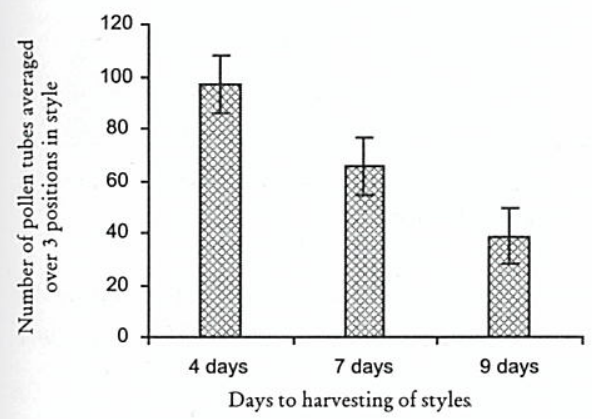

Figure 3. Average number of pollen tubes and associated standard error of $M$. alternifolia at increasing intervals from pollination (November 2005)

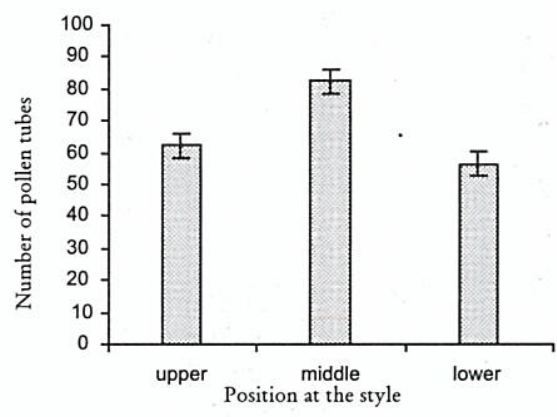

Figure 4. Average number of pollen tubes and associated standard errors of $M$. alternifolia at different positions on the style (November 2005) 


\section{B. Second Experiment}

As described in Materials and Methods, the pollen used for cross-pollination in this experiment (November 2006) was a mix from trees in four different families. The result shows that the average number of pollen tubes varied between type of cross (Figure 5; Wald stat $=427.8$, d.f. $=8, \chi=<0.001$ ). There was a great variation in the average number of pollen tubes between self-, cross-, and open-pollination, with fewer pollen tubes resulting from self-pollination compared to cross- and openpollination. Figure 5 shows that average number of pollen tubes varied between sample trees, which family number 32 showed more average number of pollen tubes compared to other families. The variations of number pollen tubes between sample trees indicate the variation of self-sterility between the three sample trees.

As in the preceding experiment, the average number of pollen tubes detected in the style also declined with the time from pollination to style harvesting (Figure 6), but the difference was not statistically significant (Wald stat $=7.7$, d.f. $=2, \chi$ $=0.052$ ). There were significant differences in the number of pollen tubes with position on the style (Figure 7; Wald stat $=53.84$, d.f. $=2, \chi=<0.001$ ); the number of pollen tubes in the middle of the style was greater than those in its upper and lower sections.

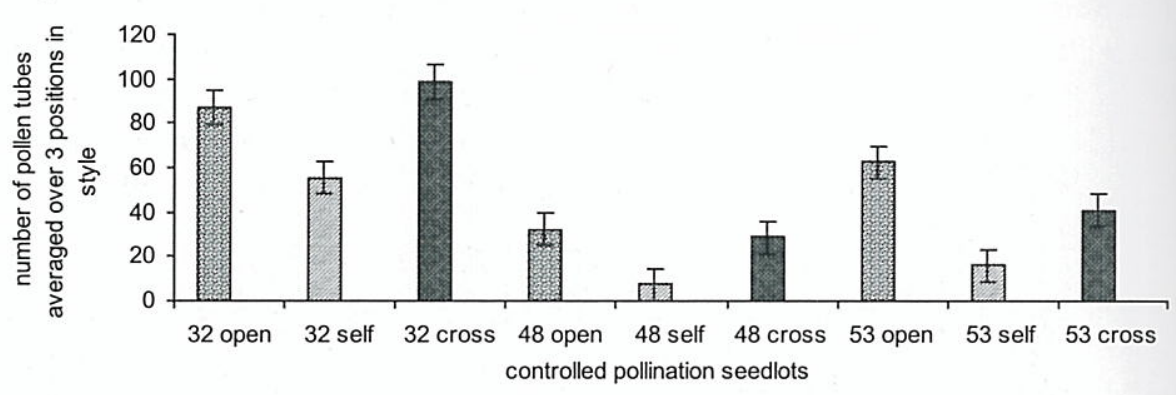

Figure 5. The average number of pollen tubes over 3 positions in style and associated standard errors for self-, open- and cross-pollination treatments (November 2006)

Observations of the ovules using fluorescence microscope suggest that no ovules were penetrated by pollen tubes at 4, 7, and 9 days after pollination. Some penetration was recorded 14 days after pollination. Analysis of data from 14 days after pollination shows that the number of pollen tubes penetrating the ovules varied between pollination treatment (Table 1 ; Wald stat $=53.5$, d.f. $=2, \chi=$ $<0.001$ ), with cross-pollination resulting in the highest average number of ovules penetrated by pollen tubes, followed by open- and then self-pollination treatments. Pollen tubes were observed to have penetrated ovules at the micropyle (Figure 
8) and generally had grown through the nucleus tissue towards the embryo sacs (Pound et al., 2002a).

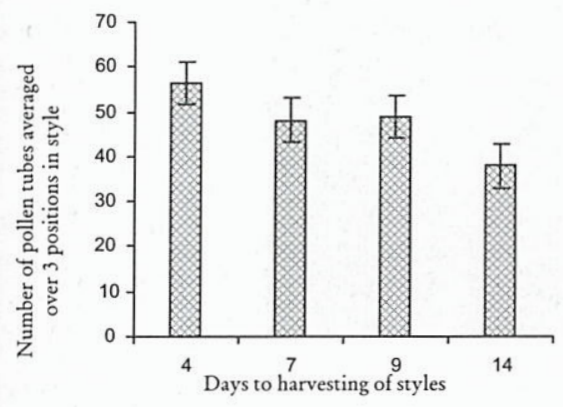

Figure 6. Average number of pollen tubes and associated standard errors of $M$. alternifolia at increasing intervals from pollination (November 2006)

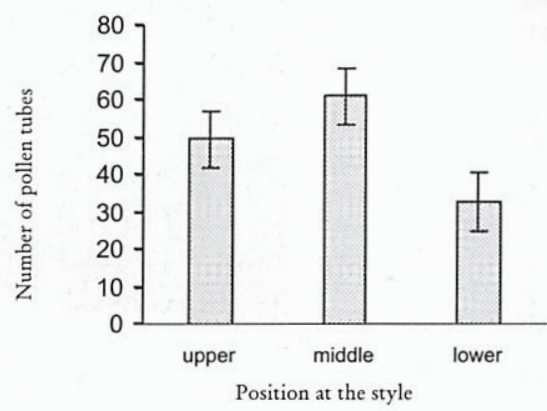

Figure 7. Average number of pollen tubes and associated standard errors of $M$. alternifolia by position in the style (November 2006)

Table 1. Average of ovule penetrated by pollen tubes from self-, cross-, and open-pollination, 14 days after pollination (November 2006)

\begin{tabular}{cccc}
\hline \multirow{2}{*}{ Sample tree } & \multicolumn{3}{c}{ Number of penetrated ovules per flower (\%) } \\
\cline { 2 - 4 } & Self-pollinated & Cross-pollinated & Open-pollinated \\
\hline \multirow{2}{*}{48} & 0.12 & 7.5 & 0.8 \\
32 & 0.21 & 4.2 & 1.3 \\
53 & 0.15 & 5.3 & 1.3 \\
\hline
\end{tabular}




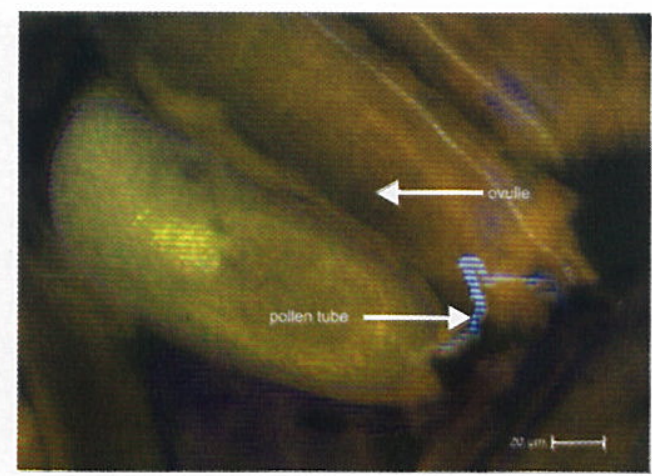

Figure 8. Fluorescence micrograph of arrested pollen tube in the ovule 2 weeks after cross-pollination, the hypanthium was stained with aniline blue (November 2006)

The rate of pollen tube growth in $M$. alternifolia is slow compared to that of angiosperms (Heslop-Harrison, 1971). Results from 2005 observation shows that pollen tubes do not grow between the cells of the transmitting tissue in the centre of the style for 48 hours, and only reach the base of the style 4 days after pollination. The results reported here are, however, similar to those reported for other member of the Myrtaceae, such as E. regnans, Leptospermum myrsinoides, L. continentale, Chamelaucium uncinatum and Metrosideros excelsa (Griffin et al., 1987; Sedgley et al,. 1989; O'Brien and Calder, 1993; O’Brien, 1996; Schmidt-Adam et al., 1999).

The reduction in number of pollen tubes from the upper part to the lower part of the style, i.e. from the stigma to the ovaries, suggests some selection between pollen tubes is occurring in the style. This may result from competition for space to penetrate the stigma and enter the style, or competition between the fastest growing tubes to reach the loculus and the ovaries (Ellis and Sedgley, 1992; O'Brien, 1996). Moreover, pollen presenter and upper style are recognized as the control points in pollen tube growth (Fuss and Sedgley, 1991). The pollen presenter has a different morphology from the rest of the style, with an abundance of transfer cells surrounding the transmitting tissue (Clifford and Sedgley, 1993). The upper style is the next controlling region, with smaller numbers of pollen tubes inhibited in the pollen presenter (Maguire and Sedgley, 1998). The results from two different periods of observation demonstrate that the number of pollen tubes following self-pollination was less than that from cross-pollination and open-pollination; this result also showed that rejection of self-pollen tubes occurs in the style as a mechanism of self-incompatibility. Rejection in the stigma or the style is a common self-incompatibility mechanism in plants (de Nettacourt, 1977; Lewis, 1979), which was demonstrated in E. woodwardii flowers (Sedgley and Smith, 1989). The results of this study, that $M$. alternifolia flowers are preferentially outcrossing, confirms the result of a previous study based on outcrossing rate (Butcher et al., 1992). 
Pollen tubes resulting from self-pollination are also capable of penetrating the ovules, but only a few do so compared to cross- and open-pollination (Table 1). This is consistent with the results reported in E. woodwardii (Sedgley and Smith, 1989). Suggesting that a late-acting self-incompatibility mechanism, such as that found in other woody species (Bawa et al., 1985; Seavy and Bawa, 1986), is also active in M. alternifolia. In conjunction with the rejection of pollen tubes in the style, it suggests that $M$. alternifolia has multiple barriers to self-pollination. The level of self incompatibility varies among the Myrtaceae. For example, Potts and Savva (1988) found complete sterility in E. morrisbyi with no seed production after self pollination; Sedgley and Smith (1989) reported that $E$. woodwardii showed partial self incompatibility since self-pollination resulted in reduced capsule retention and seed development as compared with cross-pollination; this also occurs in E. grandis (Hodgson, 1976). Sedgley and Smith (1989) concluded that the lack of seed set from self-pollination in $E$. woodwardii was due to a lack of penetration of ovules by the self pollen tubes rather than a post-zygotic mechanism. However, Griffin et al. (1987) and Ellis and Sedgley (1992) described a post-zygotic mechanism operating in E. regnans, as well as in E. spathulata, E. cladocalyx and E. leptophylla. Pound et al. (2002a) reported that four of five trees of E. globulus spp. globulus were either $100 \%$ self-incompatible or greater than $99 \%$ self-incompatible, indicating that a very strong mechanism operated to prevent selfed seed from being produced. Pound $e t$ al. (2002a) concluded that self incompatibility within Eucalyptus can be a complex mechanism.

Abnormality of pollen tubes in self-pollinated crosses, such as disorientation of growth, irregular tubes and spiraling tubes in the self-pollination style, was evident in this study (Figure 1.B and 1.C). A higher number of pollen tube abnormalities were found in self-pollinated flowers than those subjected to cross- and openpollinations.

In this study, more than $50 \%$ of ovules samples observed 2 weeks after pollination did not show penetration by a pollen tube. This probably due to the ovules being harvested too early, prior to fertilization; or the physical action of preparing ovules for microscopic examination, which involved squashing the specimen, may have caused pollen tubes to be pulled out of the micropyles. Unclear results of pollen tubes in the ovules due to the inappropriate methods were also found in E. globulus (Pound et al., 2002b) and E. nitens (Pound et al., 2003). In this case, a more extended time for observing fertilization of the ovules of $M$. alternifolia is suggested; embryological studies should be undertaken to help provide clearer results.

\section{CONCLUSION}

Less pollen tube was found in the self-pollinated styles than cross-pollinated styles. However, the result shows that mechanism of self-incompatibility occurs in this species. The rejection of self-pollen tubes at the ovarian level confirmed that pre-zygotic incompatibility system occurred in $M$. alternifolia. 


\section{ACKNOWLEDGEMENTS}

The author is very grateful to Prof. Peter Kanowski, Dr. John Doran, Mr. Mike Moncur for their invaluable comments and supports. Thanks are also due to Dr. Sally Stowe and Dr. Cheng Huang for fluorescence microscopy assistance and Dr. Emlyn Williams for his support in statistical analysis.

\section{REFERENCES}

Barlow, B.A. and J. Forrester. 1984. Pollen tube interaction in Melaleuca. In: E.G. Williams and R.B. Knox (Eds.), Pollination '84: 154-160. The School of Botany, University of Melbourne, Australia.

Baskorowati, L. 2006. Controlled Pollination Methods for Melaleuca alternifolia (Maiden and Betche) Cheel. ACIAR Technical Report 63. ACIAR, Canberra. 16p.

Baskorowati, L. 2008. Reproductive Biology of Melaleuca alternifolia (Maiden \& Betche) Cheel. Doctor of Philosophy Thesis, The Fenner School Resource Environment and Society, The Australian National University, Canberra, Australia. 167p.

Bawa, K.S. 1974. Breeding systems of tree species of a lowland tropical community. Evolution 28: 85-92.

Bawa, K.S. and J.H. Beach. 1983. Self-incompatibility systems in the Rubiaceae of a tropical lowland rainforest. American Journal of Botany 70: 1281-1288.

Bawa, K.S., S.H. Bullock, D.R. Perry, R.E. Coville, and M.H. Grayum. 1985. Reproductive biology of tropical lowland rain forest trees: II Pollination Systems. Australian Journal of Botany 72: 346-356.

Butcher, P.A., J.C. Bell, and G.F. Moran. 1992. Patterns of genetic diversity and nature of the breeding system in Melalenca alternifolia (Myrtaceae). Australian Journal of Botany 40: 365-375.

Clifford, S.C. and M. Sedgley. 1993. Pistil structure of Banksia menziessii R.Br. (Proteaceae) in relation to fertility. Australian Journal of Botany 41: 481-490.

de Nettacourt, D. 1977. Incompatibility in Angiosperms. Springer Verlag, New York. 230p.

Doran, J.C. and G.F. Moran. 2002. Development of DNA markers for breeding of tea tree. A report for the Rural Industries Research and Development Corporation. CSIRO, Canberra. 39p.

Ellis, M.F. and M. Sedgley. 1992. Floral morphology and breeding system of three species of Eucalyptus, section Bisectaria (Myrtaceae). Australian Journal of Botany 40: 249-262. 
Franklin-Tong, N.V.E. and C.H. Franklin. 2003. Gametophytic self-incompatibility inhibits pollen tube growth using different mechanisms. Trend in Plant Science 8: 598-605.

Fuss, A.M. and M. Sedgley. 1991. Polen tube growth and seed set of Banksia coccinea R.Br. (Proteaceae). Annals of Botany 68: 377-384.

Griffin, A.R., K.K. Ching, K.W. Johnson, F.C. Hand, and I.P. Burgess. 1982. Processing Eucalyptus pollen for use in controlled pollination. Silvae Genetica 31: 198-203.

Griffin, A.R., G.F. Moran, and Y.J. Fripp. 1987. Preferential outcrossing in Eucalyptus regnans F. Muell. Australian Journal of Botany 35: 465-475.

Hodgson, L.M. 1976. Some aspects of flowering and reproductive behaviour in Eucalyptus grandis (Hill) Maiden. 1: Flowering, controlled pollination methods, pollination and receptivity. South African Forestry Journal 97: 18-28.

Heslop-Harrison, J. 1971. Pollen - Development and Physiology. Butterworths, London. 338p.

Kartikawati, N.K. 2005. Tingkat inkompatibilitas bersilang sendiri pada tanaman kayu putih. Jurnal Penelitian Hutan Tanaman 2: 141-147.

Lewis, D. 1979. Sexual incompatibility in plants. University Park Press, Baltimore. Pp. 59.

Maguire, T.L. and M. Sedgley. 1998. Interspecific and intergeneric pistil-pollen compatibility of Banksia coccinea (Proteaceae). Australian Journal of Botany 46: 453-463.

Martin, F.W. 1959. Staining and observing pollen tubes in the style by means of fluorescence. Stain Technology 34: 125-128.

O'Brien, S.P. and D.M. Calder. 1993. Reproductive biology and floral phenologies of the sympatric species Leptosperum myrsionoides and L. continentale (Myrtaceae). Australian Journal of Botany 41: 527-539.

O'Brien, S.P. 1994. Pistil structure and pollen tube pathways in Leptospermum myrsinoides and L. continentale (Myrtaceae). Annals of Botany 73: 225-230.

O'Brien, S.P. 1996. Timetable of stigmatic receptivity and development and pollen tube growth in Chamelaucium ucinatum. Australian Journal of Botany 44: 649-659.

Potts, B.M. and M. Savva. 1988. Self-incompatibility in Eucalyptus. In: R.B. Knox., M.B. Singh, and L.F. Troiani (Eds.). Pollination '88. The School of Botany, University of Melbourne, Australia, Pp. 165-175.

Potts, B.M. and P. Gore. 2000. Reproductive biology and controlled pollination of Eucalyptus - a review. Symposium on Hybrid Breeding and Genetics. Noosa, 
Australia. Queensland Government, Queensland Department of Primary Industry and Queensland Forestry Research Institute. 68p.

Pound, L.M., M.A.B. Wallwork, B.M. Potts, and M. Sedgley. 2002a. Selfincompatibility in Eucalyptus globulus ssp. globulus (Myrtaceae). Australian Journal of Botany 50: 365-372.

Pound, L.M., W.A.B. Wallwork, B.M. Potts, and M. Sedgley. 2002b. Early ovule development following self- and cross-pollination in Eucalyptus globulus Labill. ssp. globulus. Annals of Botany 89: 613-620.

Pound, L.M., M.A.B. Wallwork, B.M. Potts, and M. Sedgley. 2003. Pollen tube growth and early ovule development following self- and cross-pollination in Eucalyptus nitens. Sex Plant Reproductive 16: 58-69.

Richards, A.J. 1997. Plant Breeding Systems. Chapman and Hall, Cambridge. 529p.

Rosseto, M., R.W. Slade, P.R. Baverstock, R.J. Henry, and L.S. Slee. 1999. Microsatelite variation and assessment of genetic structure in tea tree (Melaleuca alternifolia - Myrtaceae). Molecular Ecology 8: 633-643.

Sage, T.L., R.I. Bertin, and E.G. Williams. 1994. Ovarian and other late-acting selfincompatibility systems. In: E.G. Williams, A.E. Clarke, and R.B. Knox (Eds.), Genetic Control of Self-incompatibility and Reproductive Development in Flowering Plants. Kluwer Academic Publishers, London. Pp. 116-140.

Schmidt-Adam, G., K.S. Gould, and B.G. Murray. 1999. Floral biology and breeding system of pohutukawa (Metrosideros excelsa, Myrtaceae). New Zealand Journal of Botany 37: 687-702.

Seavy, S.R. and K.S. Bawa. 1986. Late acting self-incompatibility in Angiosperms. Botanical Review 52: 196-219.

Sedgley, M. and A.R. Griffin. 1989. Sexual Reproduction of Tree Crops. Academic Press, London. 376p.

Sedgley, M., F.C. Hand, R.M. Smith, and A.R. Griffin. 1989. Pollen tune growth and early seed development in Eucalyptus regnans. B. Muell. in relation to ovule structure and preferential outcrossing. Australian Journal of Botany 37: 397-411.

Sedgley, M. and L. Granger. 1996. Embryology of Eucalyptus spatulata and E. platypus (Myrtaceae) following selfing, crossing and reciprocal interspesific pollination. Australian Journal of Botany 44: 661-671.

Sedgley, M. and R.M. Smith. 1989. Pistil receptivity and pollen tube growth in relation to the breeding system of Eucalyptus woodwardii (Symphyomyrtus: Myrtaceae). Annals of Botany 64: 21-31. 